HETEROCYCLES, Vol. 104, No. 1, 2022, pp. 185 - 190. @ 2022 The Japan Institute of Heterocyclic Chemistry Received, 5th October, 2021, Accepted, 25th October, 2021, Published online, 2nd November, 2021 DOI: $10.3987 / C O M-21-14567$

\title{
ISOLATION OF PEPTIDOLIPIN NA DERIVATIVES FROM THE CULTURE OF NOCARDIA ARTHRITIDIS IFM10035' IN THE PRESENCE OF MOUSE MACROPHAGE CELLS
}

\section{Yasumasa Hara, ${ }^{1,2 *}$ Daiki Tanimura, ${ }^{1}$ Teruhisa Manome, ${ }^{1}$ Midori A. Arai, ${ }^{3}$ Takashi Yaguchi, ${ }^{4}$ and Masami Ishibashi ${ }^{1,2 *}$}

\begin{abstract}
${ }^{1}$ Graduate School of Pharmaceutical Sciences, Chiba University, 1-8-1 Inohana, Chuo-ku, Chiba 260-8675, Japan. ${ }^{2}$ Plant Molecular Science Center, Chiba University, 1-8-1 Inohana, Chuo-ku, Chiba 260-8675, Japan. ${ }^{3}$ Department of Biosciences and Informatics, Faculty of Science and Technology, Keio University, 3-14-1 Hiyoshi, Kohoku-ku, Yokohama, Kanagawa 223-8522, Japan. ${ }^{4}$ Medical Mycology Research Center, Chiba University, 1-8-1 Inohana, Chuo-ku, Chiba 260-8673, Japan. E-mail: mish@chiba-u.jp and yhara@chiba-u.jp
\end{abstract}

\begin{abstract}
We isolated two peptidolipin NA derivatives, L-Val (6) peptidolipin NA and peptidolipin NA, named as compounds $\mathbf{1}$ and 2, respectively. These compounds were produced in the co-culture extracts of Nocardia arthritidis IFM $10035^{\mathrm{T}}$ and the mouse macrophage cell line $\mathrm{J} 774.1$, but not in the single culture of $N$. arthritidis. Among the two compounds along with nocarjamide (3) isolated from the co-culture of $N$. tenerifensis and J774.1, compounds $\mathbf{1}$ and $\mathbf{3}$ showed higher cytotoxicity against $\mathrm{J}_{774}$.1, with $\mathrm{IC}_{50}$ values of $116 \mu \mathrm{M}$ and $25 \mu \mathrm{M}$, respectively. In addition, compound 1 showed a TRAIL-resistance-overcoming activity in the human gastric adenocarcinoma AGS cells.
\end{abstract}

The genus Nocardia consists of approximately 120 species, including N. farcinica, N. asteroids, N. nova, and $N$. brasiliensis. Numerous species of this genus are known to exist in the water and soil. However, some species of Nocardia are present in the human skin, lungs, and other organs as pathogens. The pathogenic species of Nocardia produce many bioactive compounds, such as nocobactin NA (from $N$. farcinica $^{1}$ ) and nocardithiocin (from N. pseudobrasiliensis ${ }^{2}$ ). Thus, pathogens of the genus Nocardia can be a rich resource of natural products. We previously suggested a method for screening new natural compounds from Nocardia in the presence of animal cells and isolated two new compounds, 
dehydropropylpantothenamide and nocarjamide. ${ }^{3,4}$ In the present study, we describe the isolation of two known compounds using the co-culture method. We isolated L-Val (6) peptidolipin NA (1) ${ }^{5}$ and peptidolipin NA $(2)^{6}$ from the culture of $N$. arthritidis IFM10035 $5^{\mathrm{T}}$ in the presence of mouse macrophage cell line J774.1. Compound 1 showed cytotoxicity against J774.1, with an $\mathrm{IC}_{50}$ of $116 \mu \mathrm{M}$. In addition, compound 1 showed TRAIL-resistance-overcoming activity in the human gastric adenocarcinoma AGS cells.

In our previous study, we classified the genus Nocardia into nine clades using DNA sequence for $16 \mathrm{~S}$ rRNA sequencing and selected 13 species from them. ${ }^{7}$ In this study, we aimed to discover various bioactive natural products from the genus Nocardia ${ }^{8,9}$ Accordingly, we performed the NF- $\kappa$ B luciferase assay and LCMS analysis to screen for natural products from the single culture and co-culture (cultured in the presence of J774.1) extracts of the 13 species of Nocardia. The co-culture extract of $N$. arthritidis IFM10035 ${ }^{\mathrm{T}}$ suppressed NF- $\mathrm{KB}$ signaling and had several specific peaks in LCMS compared to the single culture extract of $N$. arthritidis. This strain was cultured in modified Czapek-Dox liquid medium ${ }^{10}$ in the presence of J774.1. After centrifugation of the culture extract, the methanolic $(\mathrm{MeOH})$ extract of the mycelium cake was partitioned between ethyl acetate (EtOAc) and water. The EtOAc layer was fractionated by silica gel, and the fractionation was tested by an NF- $\kappa \mathrm{B}$ signal-suppressing activity test. After the EtOAc layer was fractionated, only two fractions showed a low level of suppression of the NF- $\kappa \mathrm{B}$ signal. The fractions were further subjected to ODS column chromatography; however, none of the fractions showed an NF- $\mathrm{BB}$ signal suppressing activity. Therefore, to search for the specific peaks in LCMS obtained from the co-culture extracts, we used the reverse-phase HPLC that ultimately yielded two natural products, which we named compounds 1 and $\mathbf{2}$ (Figure 1).

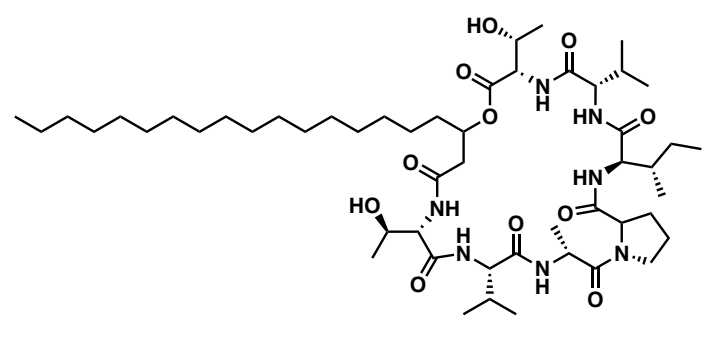

1
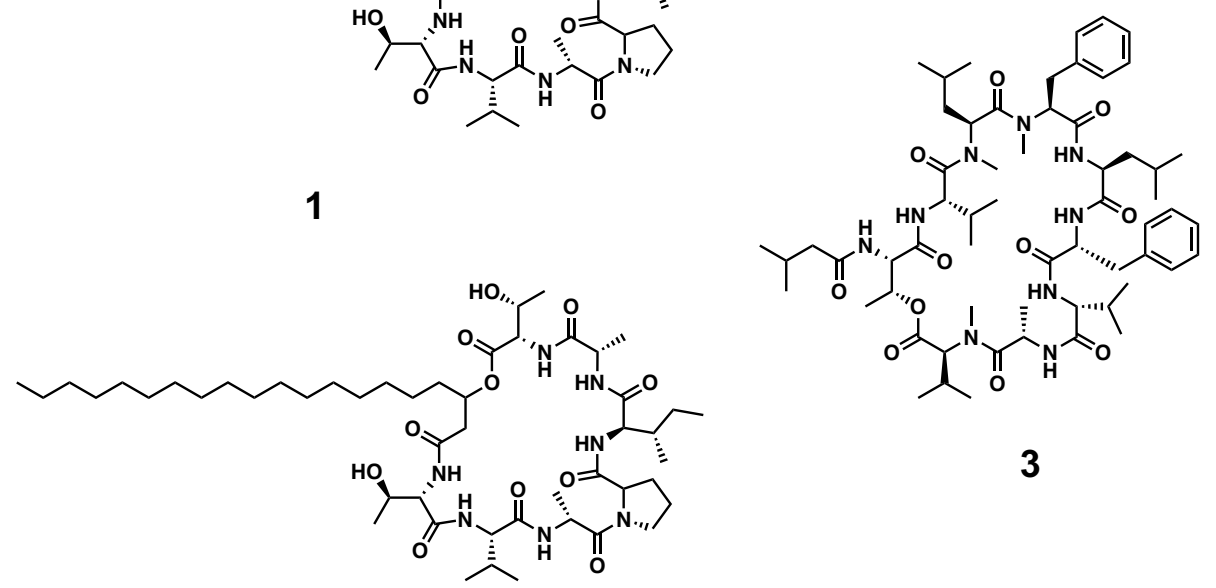

3

2

Figure 1. Compounds 1 and $\mathbf{2}$ isolated from Nocardia arthritidis IFM10035 ${ }^{\mathrm{T}}$ and nocarjamide (3). 
Upon a detailed NMR and mass spectrometry analysis, compounds $\mathbf{1}$ and $\mathbf{2}$ were identified as two known compounds, L-Val (6) peptidolipin NA and peptidolipin NA, respectively. These compounds were previously isolated from a single culture extract of $N$. asteroides ATCC 9969. ${ }^{5,6}$ In this study, compounds 1 and 2 isolated from not the single culture but the co-culture with $\mathbf{J} 774.1$ using $N$. arthritidis, which is a different species from $N$. asteroides.

For pathogenic microorganisms, escaping the cellular immunity mediated by macrophages is critical for attacking the host. For instance, nocobactin NA produced from $N$. farcinica may be cytotoxic to mouse macrophages. ${ }^{11}$ Hence, we tested compounds $\mathbf{1}$ and $\mathbf{2}$ for their cytotoxicity against the mouse macrophage cell line J774.1, along with nocarjamide (compound 3, Figure 1), which was isolated from the culture of $N$. tenerifensis in the presence of J774.1. ${ }^{4}$ Compounds $\mathbf{1}$ and $\mathbf{3}$ showed cytotoxicity with $\mathrm{IC}_{50}$ values of $116 \mu \mathrm{M}$ and $25 \mu \mathrm{M}$, respectively (Figure 2). Compound 2 showed cytotoxicity with an $\mathrm{IC}_{50}$ value of $>200 \mu \mathrm{M}$. These results suggested the pathogenic Nocardia may produce some compounds that attack immune cells to contribute to host invasion. Since compounds $\mathbf{1}$ and $\mathbf{2}$ showed low cytotoxicity, we wanted to examine whether these compounds have other biological functions. Therefore, we tested these compounds for the tumor necrosis factor-related apoptosis-inducing ligand (TRAIL) resistance overcoming activity. ${ }^{12}$ TRAIL induces apoptosis by the activation of caspases only in cancer cells, and these TRAIL-resistant cancer cells exist in several organs including breasts and lungs. When we treated the TRAIL-resistant human gastric adenocarcinoma AGS cells with TRAIL alone, the cells mostly survived. However, upon treating the cells with TRIAL along with compound 1, the cell's viability decreased. The differences in the cell viability between treatment with compound $\mathbf{1}$ alone and treatment with compound $\mathbf{1}$ and TRAIL were $26 \%$ at 100 $\mu \mathrm{M}$ and $43 \%$ at $200 \mu \mathrm{M}$ of compound 1 (Figure 3). This indicates that compound 1 may activate apoptosis in TRAIL-resistant human cancer cells.
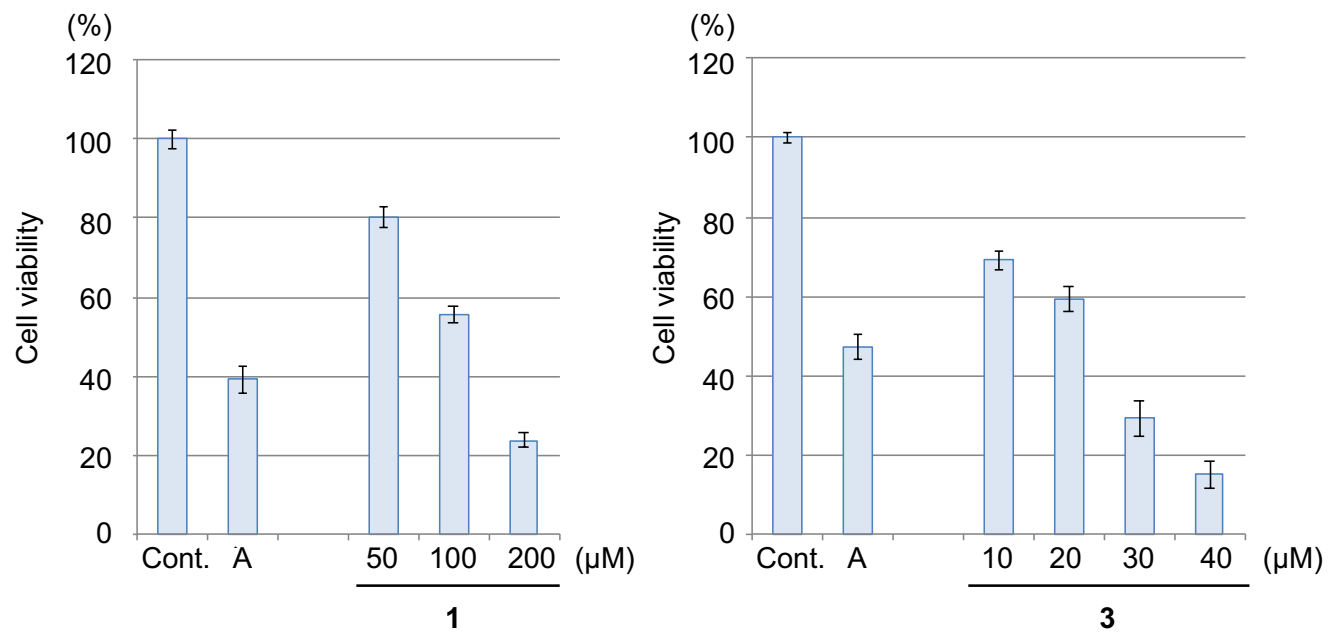

Figure 2. Cell viability of J774.1 cells against compounds $\mathbf{1}$ and $\mathbf{3}$.

Cont.: $0.1 \%$ DMSO as a control, A: actinomycin $\mathrm{D}(0.05 \mu \mathrm{M})$ as a positive control. 


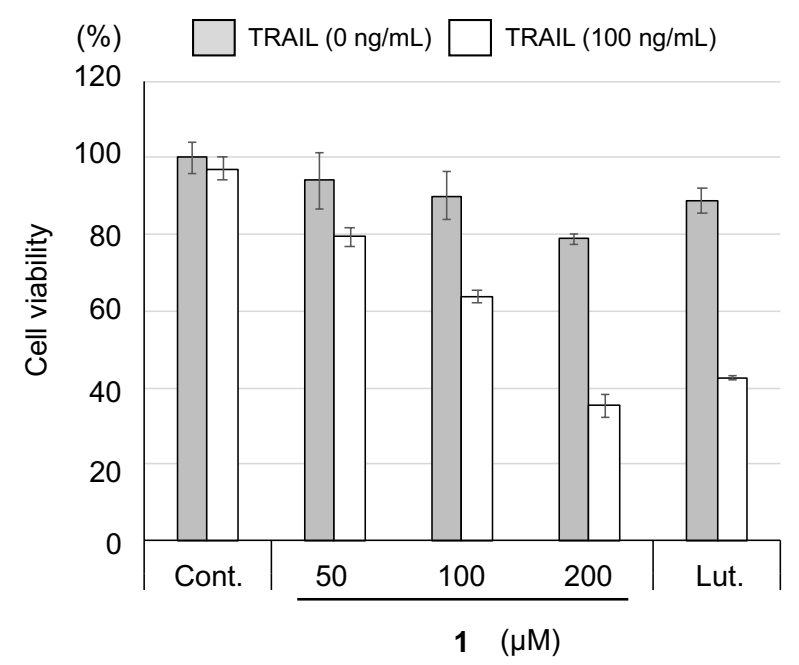

Figure 3. TRAIL resistance overcoming activity for compound $\mathbf{1}$.

Cont.: $0.1 \%$ DMSO as a control, Lut.: luteolin $(17.5 \mu \mathrm{M})$ as a positive control.

In the present study, we isolated two peptidolipin NA derivatives $(\mathbf{1}, \mathbf{2})$ from the co-culture of $N$. arthritidis IFM10035 ${ }^{\mathrm{T}}$ and the mouse macrophage cell line J774.1. These compounds were not produced in single culture of $N$. arthritidis. Compound 1 showed cytotoxicity against $\mathrm{J} 774.1$, with an $\mathrm{IC}_{50}$ of $116 \mu \mathrm{M}$. In addition, compound $\mathbf{1}$ showed TRAIL-resistance-overcoming activity.

\section{EXPERIMENTAL}

\section{General experimental procedures}

The following instruments were used in the present study: a P-2200 polarimeter (JASCO) for optical rotations; a J-1100 CD spectrophotometer (JASCO) for circular dichroism; a UV 1280 (Shimadzu) for UV-visible spectrophotometer; an ECZ-600 spectrometer (JEOL) for NMR spectroscopy (solvent chemical shifts were used as the internal standard); an LCMS 2020 (Shimadzu) for ESI-MS; an LC-20AD (Shimadzu) pump and SPD-M20A (JASCO) for HPLC. The following adsorbents were used for purification: silica gel $60 \mathrm{~F}_{254}\left(0.25 \mathrm{~mm}\right.$, Merck) and silica gel $60 \mathrm{RP}-18 \mathrm{~F}_{254 \mathrm{~S}}(0.25 \mathrm{~mm}$, Merck) for analytical thin-layer chromatography (TLC); Silica gel $60 \mathrm{~N}$ (Kanto Chemical Co., Inc.) and Chromatorex ODS (Fuji Silysia) for column chromatography; COSMOSIL Cholester $(\phi 10.0 \times 250 \mathrm{~mm}$, Nacalai Tesque) for preparative HPLC.

\section{Microbial strain}

The Nocardia strains were stored in a freeze-dried state at the Medical Mycology Research Center, Chiba University, Japan. These strains were identified by $16 \mathrm{~S}$ rRNA gene sequencing.

\section{Fermentation and isolation}

Nocardia arthritidis IFM10035 ${ }^{\mathrm{T}}$ was cultured in the presence of the mouse macrophage cell line J774.1, in 
a modified Czapek-Dox medium at $28^{\circ} \mathrm{C}$ for 2 weeks using a previously reported method. ${ }^{4}$ Subsequently, the culture broth (1 L) was centrifuged at $4500 \mathrm{rpm}$ for $20 \mathrm{~min}$ to obtain the supernatant and mycelium cake. The mycelial cake was extracted with $\mathrm{MeOH}(1 \mathrm{~L} \times 3)$. The $\mathrm{MeOH}$ extract was partitioned between EtOAc $(1 \mathrm{~L} \times 3)$ and water to obtain the EtOAc extract $(100.3 \mathrm{mg})$. The EtOAc extract was subjected to silica gel column chromatography $\left(\phi 20 \times 150 \mathrm{~mm}, \mathrm{CHCl}_{3}-\mathrm{MeOH}\right.$ system $)$ to obtain fractions $1 \mathrm{~A}-1 \mathrm{I}$. Fraction $1 \mathrm{C}$ $\left(\mathrm{CHCl}_{3}: \mathrm{MeOH}=20: 1,29.0 \mathrm{mg}\right)$ was subjected to ODS column chromatography $(\phi 20 \times 150 \mathrm{~mm}$, $\mathrm{H}_{2} \mathrm{O}-\mathrm{MeOH}$ system) to obtain fractions $2 \mathrm{~A}-2 \mathrm{~F}$. Fraction $2 \mathrm{~B}\left(\mathrm{H}_{2} \mathrm{O}: \mathrm{MeOH}=1: 9,18.7 \mathrm{mg}\right)$ was subjected to reverse-phase HPLC (COSMOSIL Cholester [ $\phi 10.0 \times 250 \mathrm{~mm}$ ]; eluent: 95\% $\mathrm{MeOH}$; flow rate: $5 \mathrm{~mL} / \mathrm{min}$ ) to isolate compounds $2\left(2.2 \mathrm{mg}, t_{\mathrm{R}} 15.3 \mathrm{~min}\right)$ and $\mathbf{1}\left(3.4 \mathrm{mg}, t_{\mathrm{R}} 22.8 \mathrm{~min}\right)$.

\section{L-Val (6) peptidolipin NA (1)}

ESI-MS: $m / z 993[\mathrm{M}+\mathrm{H}]^{+} .[\alpha]_{\mathrm{D}}^{24}-12(c 1.0, \mathrm{MeOH}) . \mathrm{UV} \lambda_{\max }(\mathrm{MeOH}) \mathrm{nm}(\log \varepsilon): 197.4$ (7.89). IR (ATR) $\mathrm{cm}^{-1}: 3280,2930,1640,1540$, and 1270. $\mathrm{CD} \lambda_{\max }(\mathrm{MeOH}) \mathrm{nm}(\Delta \varepsilon) 208$ (69.2) and 232.5 (-83.9).

\section{Peptidolipin NA (2)}

ESI-MS: $m / z 965[\mathrm{M}+\mathrm{H}]^{+}$.

\section{Cell cytotoxicity assay}

Cell viability was measured using the fluorometric microculture cytotoxicity assay (FMCA). ${ }^{13}$ Mouse macrophage cells (J774.1) were seeded at a density of $4 \times 10^{3}$ cells/well in a 96 -well black microplate and pre-cultured in $\mathrm{CO}_{2}$ incubator at $37^{\circ} \mathrm{C}$. After incubation for $24 \mathrm{~h}$, the medium was removed, and $200 \mu \mathrm{L}$ of Dulbecco's modified Eagle's medium (DMEM) with 10\% fetal bovine serum (FBS) containing the test sample adjusted to an appropriate concentration was added to each well. The cells were then cultured for 72 h. After removing the medium, the cells were washed once with $200 \mu \mathrm{L}$ phosphate-buffered saline (PBS), and $200 \mu \mathrm{L}$ fluorescein diacetate solution $(3.5 \mu \mathrm{g} / \mathrm{mL})$ was added to each well. After incubation for $1 \mathrm{~h}$, fluorescein fluorescence was measured (excitation, $485 \mathrm{~nm}$; emission, $538 \mathrm{~nm}$ ). Data are presented as the mean \pm standard deviation (SD) of three independent experiments. Dimethyl sulfoxide (DMSO) was used as the negative control. Actinomycin $\mathrm{D}(0.05 \mu \mathrm{M})$ was used as the positive control.

\section{TRAIL-resistance overcoming assay}

Human gastric adenocarcinoma cell lines (AGS) were purchased from ATCC and cultured in Roswell Park Memorial Institute-1640 medium (RPMI 1640) with 10\% FBS and 1\% penicillin-streptomycin. Cell viability of the TRIAL-resistant AGS cells was measured using the FMCA method ${ }^{13}$ in the presence and absence of TRAIL. AGS cells were seeded at a density of $1 \times 10^{4}$ cells/well in a 96 -well black microplate and pre-cultured in $\mathrm{CO}_{2}$ incubator at $37^{\circ} \mathrm{C}$. After incubation for $24 \mathrm{~h}$, the medium was removed, and 200 $\mu \mathrm{L}$ of RPMI 1640 containing the test sample adjusted to an appropriate concentration with or without TRAIL (100 ng/mL), was added to each well. The cells were then cultured for $24 \mathrm{~h}$. After removing the medium, the cells were washed once with $200 \mu \mathrm{L}$ PBS, and $200 \mu \mathrm{L}$ fluorescein diacetate solution (10 
$\mu \mathrm{g} / \mathrm{mL}$ ) was added to each well. After incubation for $1 \mathrm{~h}$, fluorescein fluorescence was measured (excitation, $485 \mathrm{~nm}$; emission, $538 \mathrm{~nm}$ ). Data are presented as the mean $\pm \mathrm{SD}$ of three independent experiments. DMSO was used as a negative control. Luteolin $(17.5 \mu \mathrm{M})$ was used as the positive control.

\section{ACKNOWLEDGEMENTS}

This work was supported by KAKENHI Grant Nos. 20H03394, 19H04640, and 20K16024 from the Japan Society for the Promotion of Science. Further, this work was partly supported by the National Bio-Resource Project, Japan (http://www.nbrp.jp/)

\section{REFERENCES}

1. C. Ratledge and G. A. Snow, Biochem. J., 1974, 139, 407.

2. A. Mukai, T. Fukai, Y. Hoshino, K. Yazawa, K. Harada, and Y. Mikami, J. Antibiot., 2009, $62,613$.

3. Y. Hara, M. A. Arai, K. Sakai, N. Ishikawa, T. Gonoi, T. Yaguchi, and M. Ishibashi, J. Nat. Med., 2018, 72, 280 .

4. Y. Hara, M. A. Arai, K. Toume, H. Masu, T. Sato, K. Komatsu, T. Yaguchi, and M. Ishibashi, Org. Lett., 2018, 20, 5831.

5. M. Guinand, M. J. Vacheron, G. Michel, B. C. Das, and E. Lederer, Tetrahedron, 1966, suppl., 7, 271.

6. a) M. Guinand and G. Michel, Biochim. Biophys. Acta, 1966, 125, 75; b) M. Ptak, A. Heitz, M. Guinand, and G. Michel, Biochem. Biophys. Res. Commun., 1980, 94, 1311.

7. S. Hara, Y. Hara, M. A. Arai, Y. Kusuya, H. Takahashi, T. Yaguchi, and M. Ishibashi, Chem. Pharm. Bull. (Tokyo), 2018, 66, 976.

8. M. A. Arai, I. Ebihara, Y. Makita, Y. Hara, T. Yaguchi, and M. Ishibashi, J. Antibiot., 2021, 74, 255.

9. S. Hara, N. Ishikawa, Y. Hara, T. Nehira, K. Sakai, T. Gonoi, and M. Ishibashi, J. Nat. Prod., 2017, 80, 565 .

10. K. Sakai, H. Komaki, and T. Gonoi, PLOS ONE, 2015, 10, e0143264.

11. Y. Hoshino, K. Chiba, K. Ishino, T. Fukai, Y. Igarashi, K. Yazawa, Y. Mikami, and J. Ishikawa, J. Bacteriol., 2011, 193, 441.

12. F. Ahmed and M. Ishibashi, Chem. Pharm. Bull. (Tokyo), 2016, 64, 119.

13. E. Lindhagen, P. Nygren, and R. Larsson, Nat. Protoc., 2008, 3, 1364. 